NBER TECHNICAL WORKING PAPERS SERIES

SOURCES OF IDENTIFYING INFORMATION IN EVALUATION MODELS

Joshua D. Angrist

Guido w. Imbens

Technicai Working Paper No. 117

NATIONAL BUREAU OF ECONOMIC RESEARCH

1050 Massachusetts Avenue

Cambridge, MA 02138

December 1991

We are grateful to Charles Manski, kobert Moffit and Geert Ridder for helpful comments, and especially to Gary chamberlain for many illuminating discussions. Part of the paper was written while the second author was visiting the Center for Economic Research at Tilburg University. This paper is part of NBER's research program in Labor studies. Any opinions expressed are those of the authors and not those of the National Bureau of Economic Research. 
NBER Technjcal Working Paper \$117 December 1991

\section{SOURCES OF IDENTIFYING INFORMATIDN IN EVALUATION MODELS}

\section{ABSTRACT}

The average effect of social programs on outcomes such as earnings is a parameter of primary interest in econometric evaluations studies. New results on using exclusion restrictions to identify and estimate average treatment effects are presented. Identification is achieved given a minimum of parametric assumptions, initially without reference to a latent index framework. Most econometric analyses of evaluation models motivate identifying assumptions using models of individual behavior. our technical conditions do not fit easily into a conventional discrete choice framework, rather they fit into a framework where the source of identifying information is institutional knowledge regarding program administration. This framework also suggests an attractive experimental design for research using human subjects, in which eligible participants need not be denied treatment. We present a simple instrumental variables estimator for the average effect of treatment on program participants, and show that the estimator attains Chamberlain's semi-parantetric efficiency bound. The bias of estimators that satisfy only exclusion restrictions is also considered.

Joshua D. Argrist

Department of Economics

Hebrew University

Mt , Scopus

Jerusalem, 91905 ISRAEL

NEER and Harvard University
Guido $w$. Imbens

Department of Economics

Harvard University

Cambridge, MA 02138 
1. Introduction. Do programs that subsidize education and training improve the labor market outcomes of program participants? Evaluation questions of this type are of great concern to government policy makers, private employers, and academic rescarchers. In any field where scientific research has policy implications, evaluation methodology is also of considerable importance. Discussions of evaluation methodology are discussions of the nature and credibility of scientific evidence. In medical research, for example, government regulations establish standards and procedures that researchers must follow for their results to be considered credible evidence for the efficacy and safety of new drugs. Standards here are quite clear: research guidelines for a new drug application clearly favol, but do not require, the randomized assigment of treatment and concurrent data collection on control groups (Center for Drug Evaluation and Research 1988, pp. 22, 56)

Social policy is arguably as important for human welfare as public heaith, yet no mutually agreed standard of evidence exista for establishing the effectiveness of social programs. On the one hand, critical research on econometric evaluation methodology by Lalonde (1986) and others has led to renewed interest in classical experinentation as a tool for social policy evaluations. Manski and Garfinkel (1991) note that the recent Job Partnerslip Training Act (JPTA) even mandates a particular sort of treatment-cortrol evaluation design in which applicants for training ate tandomly denied treatment. On the other hanel, Manski and Garfinkel (1991) and Heckman and Hotz (1989) argue persuasively that experimenls can never be a complele substitute for evaluations using observational dalia. Disagrements over 
evaluation methodology notwithstanding, research directed towards adapling experinental designs for social policy analysis and aliowing for fewer assumptions in observational analyses is likely to remain important. This paper contributes to bodls the experimental and observational components of the evahuation research agenda by prosenling new results on using exclusion restrictions to identify and estimate average lrcatment effecls.

Our findings are related to results in a number of recent papers on theoretical identification in evaluation models. Like Chamberlain (1986), Heckman (1990a) and Heckınan and Honoré (1990), we are concerned with identification given a minimum number of parametric assumptions. But, as in Manski (1990), we avoid the additive latent index framework commonly invoked in econometric evaluations. Much of the previous work on identificaLion presents some very gerreral findings regarding the jderitification of distribulions, but devotes relatively little attention to converting theoretical identification into empirically feasible estimators. In contrast, the formulation in this paper focuses on conditional means, and is inmediately usefu! to applied researchers because it provides necessary and sufficient conditions for linear instrumental variables lechniques to consistently estimate the average efect of treatment. In this, our approach is related to Angrist's (1991) use o[ instrumental variables to estimate trealment effects in nonlinear models, although here the identification conditions are not molivated by funclional form restrictions.

We also show how to ir:terpret the identifying assumplions as outlining a particular type of experimental design useful for research involying turnan subjects. Like Lcokman (fogob), 
we view social experiments as a source of identifying information, rather than as a replacement for economic modelling, and think that experiments should be designed with this in mind. An experimental design interpretation of lnstrumental Variables identification conditions is important because the resulting design may be ethically more attractive than the conventional approach to randomizalion wherein eljgible program applicants are randomly excluded from treatment. For example, some physicians have argued that randomization is incompatible with the Personal Care Principle in medical ethics, which requires doctors to put the welfare of their patients above the potential social gains fron research (Royall [1991]). JPTA program administrators are also reluctant to deny training to applicants randomized into a control group (Hotz [1991]).

Our framework for experimental design essentially consigts of first choosing an eligible population or evaluation site, either by randomized manipulation, or on the basis of ignorable (as defined by Rosenbaum and Rubin (1983]) covariates. Any eligible participant is then allowed to participate in the program if he or she likes. This approach may also identify parameters which are more likely to be useful for forecasting the impact of future programs. ${ }^{5}$

As a related by-product, our approach to inference also provides some insight regarding the problem of non-compliance in clinical trials, recently analyzed by Elron and Feldman (1991) and Robins (1989). Randomization of intention--to-treat, but not artual treatment,

\footnotetext{
Flarris (1985) and Mofhl (1991b) also discuss randomizalion of silas versus randomization of individuak. However, a key distinction is that within sites these authors argue for saturation of treatment within sites while we do not. Different average trcatmont effects are therefore ideribilied in the two types of siterandomization designs.
} 
is one way to generate exclusion restriclions that will be sufficient to identify an average treatment effect. Not surprisingly, the estimator that uses these exclusion restrictions is a form of instrumental variables.

The paper is organized as follows. Section 2 formally defines the average effect of treatment, on program participants and presents the main theoretical results. Necessary and sufficient conditions are given for a data generating process to identify an average treatment effect under exclusion restrictions. These results are also compared to previous results on the identification of treatment effects. Scetion 3 outlines the insirumental varialsas interpretation of identifying information and discusses the type of experimental design or data generating processes that satisly the identifying conditions. Some results on the efficient use of exclusion restrictions in estimating averagc treatment effects are ulso discussed. Ir section 4 we discuss what can be learned about treatment effects if the average treatment effect of interest is not jdentified. It is shown that one might still be able to derive bounds for the average treatment effect. Section 5 offers a summary and some concluding thoughts on the nature of identifying information in modeis for the evalualiou of social programs. An important distinction, and an underlying theme of L the paper, is the difference betwoen identifying information derived from models of progran participants' belavion and from information about program eligibility rules. We argue that, 1.he latter is more Jikely to provide a convincing empirical jdestification strategy.

2.1 IDENTIFJCATroN, Our framework is essentially similar to liat advaned by Rubin (1977), 
Heckman (1990), and others. Let $Y_{0}$ be the response variable for an individual if he or she does not participate in the program. We assume that $Y_{0}$ is well defined even if the individual is actually participating in the prograrn. Similarly, $Y_{1}$ is the value of the response variable if the individual does participate in the program, and $Y_{1}-Y_{0}$ is the treatment effect that we are interested in. We never observe both $Y_{0}$ and $Y_{1}$; all inferences alonut. these differences are indirect and in terms of expectations. Let $f_{0}(y)$ and $f_{1}(y)$ denote the probability density functions of $Y_{0}$ and $Y_{1}$ respectively. $P$ denotes an indicator for program parlicipalion, equal to one if an individual participates in the program, and equal to zero otherwise.

The average treatment effect can be defined in a number of ways (See, e.g., Heckman and Robb [1985|, and Heckman [1990]). First, there is the cxpcctation of $Y_{1}-Y_{0}$ in the population:

(1) $\left.\bar{\alpha}=E \mid Y_{1}-Y_{0}\right)=\int y\left[f_{1}(y)-f_{0}(y)\right] d y$

This is the expected treatiment effect if we take an individual randonly from the poptation and look at the difference between his response as a participant and no: participant. A second average treatment effect is defined by taking the expectation conditional on paslicipation:

(2) $\alpha=E\left[Y_{1}-Y_{0} \mid P=1\right]=\int y\left[\int_{1}(y \mid P=1)-f_{0}(y \mid P=1)\right] d y$

This measures low mucla a participant gains from the program. Whether the focus is on the average treatment ellect (ATE), $\bar{\alpha}_{1}$ or on the selected average trealment effect (SATE), $\alpha$, dejends on the parlicular applicalion. We arc usually in terested in forecastiug the eftects 
of a program when it is extended to a larger part of society. If the program or treatment will potentially be used by all members of the population, $\tilde{\alpha}$ is appropriate. If the program will oventually be used by a population with charactersistics similar to the pojulation in the evaluation design, $\alpha$ is the relevant average treatment eflect. The latter is probably more realistic in economic applications. We will therefore concentrate on identification of $\alpha$, rather than $\tilde{\alpha}$.

The problem of estimating average treatment effects in our framework is one of sample selection exactly the same as that considered by Gronau (1974), Hcckman (1979) and Manski (1990). We observe $Y=P \cdot Y_{1}+(1-P) \cdot Y_{0}$ and $P$. From this two condilional response distributions are identified:

$$
f_{1}(y \mid P=1) \text { and } f_{0}(y \mid P=0)
$$

along with the probability of participation, $q=\operatorname{Pr}(P=1)$. These distributions do not allow us to calculate $\alpha$ or $\alpha$, [or which we need to know lhe counter[actual expechation $E[Y \mid P=1$ ]. The difference between the mean of $Y_{1}$ for those who participatie and $Y_{0}$ for litose who do not parlicipate can be written as

$$
\begin{aligned}
& E\left[Y_{1} \mid P=1\right]-E\left[Y_{0} \mid P=0\right] \\
& =E\left[Y_{1}-Y_{0} \mid P=1\right]+E\left[Y_{0} \mid P=1\right]-E\left[Y_{0} \mid P=0\right]=0+\beta
\end{aligned}
$$

The average difference in outcomes between program parlicipants null gonpartiripants generalty confounds the treatment effect $\alpha$ and the selcction effret $\beta$. The exceptim is when 
$f_{i}(y \mid P=1)$ is equal to $f_{i}(y \mid P=0)$ for $i=0,1$ and all $y$, in which case selection is sometimes said to be ignorable. This implies that the two response distributions (with and without participation) do not depend on the decision to participate. If this is not the case then selection is non-ignorable and it is clear that we need more information, or restrictions on $f_{0}(\cdot)$, to separate $\alpha$ and $\beta$. Below we briefly review some identifying assumplions.

The first approach assumes that the selection problem can be solved simply by conditioning on the right covariates.

Condition 1 There is an observable covariate $X$ such that

$$
E\left[Y_{i} \mid P=1, X=x\right]=E\left[Y_{i} \mid P=0, X=x\right]
$$

In this case we can condition on $X$ to remove the selection effect if we observe $(Y, P, X)$ :

$$
\begin{aligned}
\alpha & =\int E\left[Y_{1} \mid P=1, X=x\right]-E\left[Y_{0} \mid P=1, X=x\right] \cdot g(x \mid P=1) d x \\
& =\int E\left[Y_{1} \mid P=1, X=x\right]-E\left[Y_{0} \mid P=0, X=x\right] \cdot g(x \mid P=1) d x
\end{aligned}
$$

This is in terms of expectations and distributions that can usually be estimated. The selection effect is equal to:

$$
\begin{aligned}
\beta= & \left.\int E\left[Y_{0} \mid P=1, X=x\right] \cdot g(x \mid P=1)-E\left[Y_{0} \mid P=0, X=x\right] \cdot g(x \mid P=0)\right] d x \\
& =\int E[Y \mid P=0, X=x] \cdot[g(x \mid P=1)-g(x \mid P=0)] d x
\end{aligned}
$$


which can also be estimated. If $g(x \mid P=1)=g(x \mid P=0)$ for all $x$, implying that $\operatorname{Pr}(P=1 \mid x)$ does not depend on $x$, selection is ignorable aftcr all and the selection eflect is zero.

Conditioning on covariates corresponds to identification by adequately controlling for all factors related to both outcomes and treatment. References for this approach include Rubin (1977) and, in a regression framework, Barnow, Cain, and Goldberger (1981). A generalized control function melhodology is outlined by Heckman and Robb (1985). An altemative approach to evaluation restricts the manner in which treatment is assigned. For example, treatment may be randomily assigned. In an experimental context, the distinction between approaches to causal inference based on control and randomization dates back at least to Fisher (1935). The econometric approach to restricing the manner of treatment assignment is to impose an exclusion restriction:

Condition 2 There is a random variable $Z$ sach that for all $z$

$$
E\left[Y_{0} \mid Z=z\right]=E\left[Y_{0}\right]
$$

and

$$
E[P \mid Z=z] \text { is a non trivial funclion of } z
$$

The covariate $Z$ affects the participation probability, but is not related to the expected response in the alssence of treatment.

Exclusion restrictions are widely used in econonetrics, usually in conjunction with other identifying restriction. One of the most influential approaches is that doveloped in a series 
of papers by Heckman $(1976,1979)$. The following example is a simplification of the model Ised by Heckman (1979):

(3) $Y=P \cdot Y_{1}+(1-P) \cdot Y_{0}=\mu+\alpha \cdot P+\varepsilon$

(4) $P=I[\gamma \cdot Z+U \geq 0]$

(5) $\left(\begin{array}{c}\varepsilon \\ U\end{array}\right) \mid Z \sim \mathcal{N}\left(\left(\begin{array}{l}0 \\ 0\end{array}\right), \Sigma\right)$

The conditional expectation of $Y_{0}$ given $Z=z$ is

$$
E\left[Y_{0} \mid Z=z\right]=\mu+E[\varepsilon \mid Z=z]=\mu
$$

and sinee participation depends on both $Z$ and $U$, it satisfies Condition 2. Notice that the treatinent effect $\alpha$ in (3) is identical for every subject, so it is equal to the average and selected average treatment effects.

Another example is Angrist's (1991) nonlincar model with an omitted variable, $U$, that is correlated with $P$, but independent of an excluded instrument $Z$ :

$$
\begin{aligned}
& E[Y \mid P=p, U=u, Z=z]=F(p, u ; \beta) \\
& E[P \mid U=u, Z=z)=G(u, z ; \gamma)
\end{aligned}
$$

and $Z$ and $U$ independent. Angrist shows that the average treatment effect

$$
\bar{\alpha}=E[F(1, U ; \beta)-F(0, U ; \beta)]
$$


is identified if and only if $F$ or $G$ is additively separable. In most of the econometric literalure identification is based on distributional assumptions, functional form assumptions regarding either the conditional expectation of the response function and the probability of participation, or both. In our main result, we investigate when the exciusion restriction outlined in condition 2 is sufficjent to identify the average treatment effect. Our approach is to invoke easily verifiable restrictions on the value of $h_{2}(z, u)$ and the distribution of $Z$.

Condition 3 There is a set $\mathcal{Z}_{0}$ such that $1>\operatorname{Pr}\left(Z \in \mathcal{Z}_{0}\right)>0, \operatorname{Pr}(P=1 \mid Z=z)=0$ for all $x \in \mathcal{Z}_{0}$.

Theorem 1 Conditions 2 and 8 are sufficicnt for idenfification of $\alpha$ with a random sample of $(Y, Z, P)$.

Proof: Let $A$ be an indicator for the event $Z \notin \mathcal{Z}^{0}$. Thren:

$$
\begin{aligned}
& E[Y \mid A=0]=E\left[Y_{0}\right] \\
& E[Y \mid A=1]=E\left[Y_{0} \mid A=1\right]+P_{r}[P=1 \mid A=1] \cdot E\left[Y_{1}-Y_{0} \mid A=1, P=1\right] \\
& \quad=E\left[Y_{0}\right]+P_{1}[P=1 \mid A=1] \cdot E\left[Y_{1}-Y_{0} \mid P=1\right]
\end{aligned}
$$

Since we can consistently estimate $\operatorname{Pr}[P=1 \mid A=1], E[Y \mid A=0]$ and $E[Y \mid A=1]$ we can identify $\alpha=E\left[Y_{1}-Y_{0} \mid P=1\right]=(E[Y \mid A=1]-E[Y \mid A=0]\} / \operatorname{Pr}(P=1 \mid A=1)$. $\mathcal{Q E D}$. 
The theorem above shows that it is sufficient for identification to have a value, or set of values, $\mathcal{Z}_{0}$, which is realized with non-zero probability and for which the probability of participation is zero. The question arises whether this is a necessary as well as a sufficient condition. A complete answer is diflicult to give. But, a number of related results suggest that it is almost impossible to achieve identification otherwise. First we note that the key to identifying $\alpha$ is the identification of $E\left[Y_{0}\right]$ :

Result $1 \alpha$ is identified if and only if $E\left[Y_{0}\right]$ is identified.

Proof: By definition $\alpha=E\left[Y_{1} \mid P=1\right]-E\left[Y_{0} \mid P=1\right]$. Note that $E\left[Y_{1} \mid P=1\right]$ is identified because we observe $Y_{\curlyvee}$ if $P=1$. Therefore identification of $\alpha$ is equivalent to identification of $E\left[Y_{0} \mid P=1\right]$. This is equal to $\left\{E\left[Y_{0}\right]-(1-\operatorname{Pr}(P=1))-E\left[Y_{0} \mid P=0\right]\right\} / \operatorname{Pr}(P=1)$. Because $E\left[Y_{0} \mid P=0\right]$ and $\operatorname{Pr}(P=1)$ are identified, identification of $E\left[Y_{\mathrm{a}} \mid P=1\right]$ is equivalent to identification of $E\left[Y_{0}\right]$.

$\Phi \mathcal{E D}$.

Second, we show that if $Z$ is a discrete random variable, Condition 3 is indeed necessary for identificalion of $E\left[Y_{0}\right]$ and therelore for identification of $\alpha$ :

Result 2 Suppose $Z$ is a discrete random variable with $K$ points of support. If $\operatorname{Pr}(P=$ $\left.1 ; Z=z_{k}\right)>0$ for all $k$, then $E\left[Y_{0}\right]$ is not identified without additional restrictions.

Proof: We can identify from the sampling design, for $k=1, \ldots, K$,

$$
E\left[Y \mid Z=z_{k}\right]=E\left[Y_{0}\right]+P_{T}\left(P=1 \mid Z=z_{k}\right) \cdot E\left[Y_{\mathrm{I}}-Y_{0}\left[Z=z_{k}\right]\right.
$$


There are $k$ equations in $k+1$ unknowns. Therefore we cannot identify $E\left[Y_{0}^{*}\right]$ without some restriction on $E\left[Y_{1}-Y_{0} \mid Z=z_{k}\right]$ if $P P_{T}\left(P=1 \mid Z=z_{k}\right]>0$ for all $k$. Note that one restriction such as equality of the conditional difference $E\left[Y_{1}-Y_{0} \mid Z=z_{k}\right]$ for $k_{1}$ and $k_{0}$ is sufficient for identification of $E\left[Y_{0}\right]$.

$\mathcal{Q E D}$.

The reason tha: Results 1 and 2 do not constitute a complete argument for sufficiency is that if $Z$ is not discrete, it might be possible to identify $E\left[Y_{0}\right]$ in certain limiting cases, even when Condition 3 fajls. In fact, this sor! of "ideritification at infinity" is an underlying thene of a number of previous results on the identification of treatment effects.

\subsection{Comparison with Previous inentification hesults, Condjtions 2 and 3 and} Theorem 1 are related to soine recent results on semi-parametric identification. In latent index models like (3)-(5), if the disturbances are normal then there is clearly no set $\mathcal{Z}_{0}$ such that the participation probability is zoro for that set. This inplics that we cannot. estimate $E\left[Y_{0}\right]=E[Y \mid A=0]$, the expected response for those who lad zero probability of participating, so that identification cannot be based on Tlueorem 1. However, one might be able to estimate $E\left[Y_{0}\right]$ in the limit. One suclt approach is Condition B in Ifeckman's (1990) theorem on nonparametric identification of treatment effects in a laten 1 -index sample sclection mode]. Hecknan requires the support of $\gamma \cdot Z$ in the latent index to be the real line. There[ore, there is a sequence of sets $Z_{n}$ such that the probalibity of participating goes to zero in the limit. That is, there is a sequence of sets $\mathcal{Z}_{n,}$ sucl that for al! sequences of real 
numbers $\eta_{n}>0$ and $\delta_{n}>0$ converging to zero, $\operatorname{Pr}\left(Z \in \mathcal{Z}_{n}\right)>\delta_{n}$, and $\operatorname{Pr}(P=1 \mid Z=z)<\eta_{n}$ for all $z \in \mathcal{Z}_{n}$. If the $\operatorname{limit}_{\lim _{n \rightarrow \infty}} E\left[Y_{0} \mid P=0, Z \in Z_{n}\right]=E\left[Y_{6}\right]$ for all such sequences $\eta_{n}$ and $\delta_{n}$, then an estimate based on such a sequence can take the place of $E_{[}\left[Y_{0} \mid A=0\right]$ in the proof of Theorem 1 and identification is still obtained. This is similar to an earlier result in Chamberlain (1986) regarding semi-parametric identification of censored regression models. Bul both Chamberlain (p. 205) and Heckman (p. 317) secm to feel that this sort of "identification at infinity" is not a very compelling foundation for inference. Chamberlain explores the possibility of imposing additional mild restrictions that would actually rule out this result.

Identification at infinity is unnatural in latent index models partly because many, if not most, regressors in economics have bounded support and are discrete. Most importantly, however, the latent index framework is usually motivated from a model of individual choice. Although the economic theory of discrete choice is well-developed and generally accepted, the details of empirical implementation are not. Identification at infuity requires not only covarjates shifting choices but excluded from outcomes, but, also a covariatc-choice relationslip that obeys additional restrictions witlout intrinsic behavioral or institutional content.

Both our Theorem 1 and previous results rely on exclusion restrictions and restrictions on the probability of participating for certain grours. Thercfore, identification under Theorem 1 is similar to identification under the results of Chamberlain (1986) and Heckman (1990). Onc essential feature, however, distinguishes our approach from the traditional econometric 
viewpoint: In Theorem 1, the main source of identifying information - the set of covariates for whorn the probability of participation is zcro - is obtained from the knowledge that the program was simply nol offered to certain individuals or groups. A latent index framework in this case is unnuatural and unnecessary; with this sort of prior information there is no nexd to rely on limiting beliavior. ${ }^{6}$

Secondly, we note that Manski (1990) presents similar results regarding identification of densily functions in selection models without reference to a latent index framework. Manski's Corollary 2 (p. 30) shows that given certain level-set restrictions, nonparametric bounds on density sunctions coincide, and therefore the density function is idenlified, if and only if the probability of selection is one for some part of the population. Like Heckman and Chamberlain, however, Manski (p. 30) seems to feel that identifying with level-set restrictions is "rarely identifying in practice." Part of the reason for this is that while the results by Manski and Heckman give identification in principle, Chamberlain proves that the information bound can be zero for these models. Our approach requires that $\operatorname{Pr}\left(Z \in Z_{0}\right)>0$, which implies that the treatment effect is estimable at rate $\sqrt{N}$.

Finally, Imbens and Angrist (1991) discuss identification of local average treatment effects. The locai average trealment effoct, $\alpha_{z w}$, is the expecled treatment effect for individuals who would change their participation status if their value of $Z$ werc clanged fron $z$ to $w$. Identification of the local average treatment effech does not require the existence of a group

\footnotetext{
'The argerment we make for identifying informalion frou progran eligibility rules is similar to that made in formally in a reornt paper by Molfit. (1991).
} 
with zero participation probability. However, the exclusion restriction must be strengthened and requires that botb $Y_{0}$ and $Y_{1}$ are independent of $Z$. In addition the relation between the instrumenl and participation is restricted. The result in Theorem 1 shows that the existence of an ineligible group directly reduces the need for untestable conditions for identification of a meaningfill average treatment effect.

Recent empirical examples of evaluations in this framework include the geographically randomized Educational Assistance Test Program (EATP) and Multiple Option Recruiting Experiment (MORE), in which different packages of veterans educational benefits were randomized over military recruitment stations (Fernandez [1982]). In the EATP and MORE, new benefit packages were not offered to a random aubsample of stations. Examples of observational research where the source of identilying information is derived from institutions include Angrist's (1990) use of the draft lottery to estimate the labor market consequences of Vietnam-era military service, Angrist and Krueger's (1989) use of birthday-ordering to estimate the effects of World War II military service, and Angrist and Krueger's (1991) use of the interaction between compulsory school attendance laws and quarter of birth to estimate the effects of compulsory schooling on earnings.

As in most econometric applications, the examples listerl above were implemented using statistical models with a constant Ireatment effect, so that the exclusion restrictions alone are sufficient for identification. But selected average treatment effects may also be identified in some of these cases. For example, in the compulsory schinoling application, virtually all 
students born in certain quarters were compelled to complete an additional year of schooling. Other students chose whether or not to continue in school; the treatment in this case is failure to complete an additional year of schooling. Likewise, in the Vietnan-era draft lottery, virtua:ly all non-deferred men with low lottery numbers were drafted. ${ }^{7}$

\subsection{Identifigation of the Average Treatment Efrect.}

II instead of the set $Z_{0}$ we had a set $\mathcal{Z}_{1}$ such that $\operatorname{Pr}(P=1 \mid Z=z)=1$ for all $z \in Z_{1}$, we would be abie to idenlify the selected average non-trentment effect:

$$
-\bar{Q}=E\left[Y_{0}-Y_{1} \mid P=0\right]
$$

The sclected average non-treatment effect measures how much non-participants gain (or lose) Irom not participating in the program. This identificalion result is obvious if we reverse what we call treatmeut and non-treatment. If these is both a set. $\mathcal{Z}_{0}$ that satisfies Condition 3 and a set. $Z_{I}$ that satisfies the above condition wo can identify the average treatment effect $\bar{\alpha}$. The three treatment effects are relaled by the following jdentity:

$$
\bar{\alpha}=\operatorname{Pr}[P=1] \cdot \alpha+(1-\operatorname{Pr}[P=1]) \cdot \bar{\alpha}
$$

Intuition for why $\alpha$ is identified is apparent from the proof of Theorem 1: $E\left[Y_{0}\right]$ is identified in the sample where $Z \in Z_{0}$, and $E\left[Y_{1}\right]$ is identified in the set where $Z \in Z_{1}$. If the treatment effect is identical for everybody tlen $\alpha=\bar{\alpha}=\bar{\alpha}$. In general however, the treatment effects for participasts and non-participants can be different, and in that case identification of the

\footnotetext{
${ }^{7}$ For the identificalion results of this paper to hold in the lot lery example, deferment would have to be an jenorable covariate.
} 
average trealment effect (ATE) requires stronger assumptions than does identification of the selccled treatment effect (SATE).

\subsection{Eligibility-Randomization as an Expenimental Design. Social experiments} can be based on the random assignment of eligibility allowing indjviduals to freely choose whet ber or not lo parlicipate. This is an alternative to experiments where randomization takes place at the later stage where individuals have already expressed a willingness to participate. ${ }^{8}$ Let $D$ be an indicator, equal to $\mathrm{I}$ if someonc is willing to participate and zero otherwige. Suppose there is some characteristic, indicated by a binary variable, $A$, where only people wilh $A=1$ are eligible for treatment. In addition, assume that the joint distribution of response $Y_{i}$ and willingness to particjpate $D$ does not depend on $A$. Formally, we can write

$$
P=A \cdot D
$$

Aild

(6) $f\left(Y_{i}, D \mid A=1\right)=f\left(Y_{i}, D \mid A=0\right)$ for $i=0,1$

The condition that is required for identification of $E\left[Y_{1}-Y_{0} \mid P=1\right]$ using Theoren 1 is that $E\left[Y_{0} \mid A=1\right]=E\left[Y_{0} \mid A=0\right]$. Equation (6) is inuch stronger than this, but it makes lhe identification stralcgy and the difference betwoen the two types of experiments trausparent.

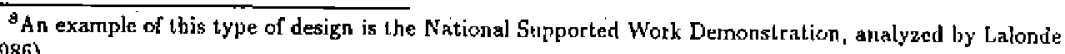
(1086).
} 
A direct consequence of $(6)$ is that $E\left[Y_{0} \mid A=a\right\}=E\left[Y_{0}\right]$ and therelore $A$ satisfies both conditions 2 and 3 and we can identify the selected average treatment eftecl

$$
\alpha=E\left[Y_{1}-Y_{0} \mid P=1\right]=E\left[Y_{1}-Y_{0} \mid D=1\right]=\frac{E[Y \mid A=1]-E[Y \mid A=0]}{\operatorname{Pr}(P=1 \mid A=1)} .
$$

T"Ye SATE is in this case the expected treatment effect for all participanta if eligibility were to be exteoded to the entire population, i.e. if $A=1$ for all individuals. ${ }^{\theta}$ The combination of the ineligibles and eligible non-participants allows us to identify the distribulion of $Y_{0}$ for those who are willing to participate:

$$
f\left(Y_{0} \mid D=1\right)=\frac{1}{\operatorname{Pr}(D=1)} f\left(\mathrm{Y}_{0} \mid A=0\right)-\frac{1-\operatorname{Pr}(D=1)}{\operatorname{Pr}(D=1)} f\left(Y_{0} \mid A=1, P=0\right),
$$

where $\operatorname{Pr}(D=1)=\operatorname{Pr}(D=1 \mid A=1)$ is identified from the proportion of participants among eligibles. One advantage of this type of experiment rather than the randomizing of applicents is that we also observe a number of individuals who do not wish to participate and therefore we can identify the selection effect $\beta$.

Harris (1985), Garfinkel, Manski and Michalopoulos (1991) and Moffit (1991) refer to experiments based on site randomization as macroexperiments, in contrast to microexperiments in which individuals within a site are randomly assigned to treatment and conlrol groups. These authors stress that such macroexperiments can potentially identify macro treatment effects that result from interaction between individuals. An importarul difference

\footnotetext{
${ }^{9}$ Our reauld differs Iron that in Meckman (1990b, p. 27) because we compare eligibles and ineligiblea whereas Heckuran compares participants and ineligibles.
} 
between our approach and previous discussion of macro experiments, however, is that we are not arguing for sațuration of treatment within eligible sites. ${ }^{10}$

A further advantage of an experiment in which eligibility is randomly assigned is that there is no formal application process for subjects who witl tater be randomized out. The need to deny treatment appears to be major factor in the dissatisfaction of job training centers with randomized assigment (Manski and Garfinkel 1991). Morcoever, in medical research, eligibility randomization does not rcquire that individual physicians deny a treatnuent they feel is beneficial (as ocurred in the controversial ECMO fextracorporeal membrane oxygenation] study of infant mortality; see Royall, [199I]). Instead of randomizing trealment within hospitals, randomly chosen hospitals could have been selected for study, with physicians freely choosing the most appropriate treatment within eligible sites, and dala collected on outcomes at all sites. Another isste of interest in medical research is the question of non-compliance in conventional clinical trials. It is clear that as long as eligibility for treatment ("intention-to-treat" in biomelric leminology) is randomized, the effect of a binary treament on participants is identified using Thoorem 1.

3.2 Linear Instrumental Variables Estimation. In this section we show that if conditions 2 and 3 are satisfied we can estimate $\alpha$ in a straightforward manner. First we discuss the case where we observe $Y, P$ and $A$, an indicator for the event $Z \notin Z_{0}$. In this

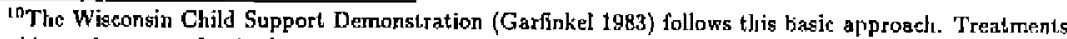
in this study are randornized over Wisconsin counties, although the focus is on county-level outcomes and not the individual outcomes captured by SATE as defined here.
} 
case we can eslimate or by linear instrumental variables. Second, we andlyze the case where we observe $Y, P$ and $Z$. If turns out that this does not necessarily increase the efficiency of our estimate of the ireatment effect. Finally we discuss estimation if we do not observe $A$ itscl, but a variable correlated with $A$.

The first estimator is a linear instrumental variables estimator. The variable $A$ is an instrument for the endogenous regressor $P$ because

$$
\text { (7) } E\left[Y^{\prime} \mid A\right]=E\left[Y_{\mathrm{a}}\right]+E[P \mid A] \cdot E\left[Y_{1}-Y_{0} \mid P=1\right]
$$

The sample analog of the solution for $\alpha$ is an estimate of $\operatorname{Cov}(y, A) / \operatorname{Cov}(P, A)$ :

$$
\hat{\alpha}=\frac{\bar{Y}_{A=1}-\bar{Y}_{A=0}}{\bar{P}_{A=1}}
$$

where $\bar{Y}_{A=1}$ and $\bar{P}_{A=1}$ are sample averages conditional on $A=1$.

The question naturally arises whether we can improve on this estimate of the selected average treatment effect if we observe $Z$ as well as $A$. Using Chamberlain's (1090) approach to semi-parametric efficiency bounds one can show that this is only possible if $Z$ affects the conditional variance of $Y_{0}$ :

Theorem 2 If the conditional variance of $Y_{\mathrm{D}}, E\left[\left(Y_{0}-E\left[Y_{0}\right]\right)^{2} \mid Z=x\right]$ does not depend on $z_{1}$ Uhen $\hat{\alpha}$ is, within the the class of regular estimators that only tuse the restrictions implied by Conditions 2 and 3 , an efficient estimator for $\alpha$. If the conditional vartance dnes depend on $z$, one can oblain a more cficient estimator hy replacing $\bar{Y}_{A=0}$ in the formila for of by an cfficient estimator for $E\left[Y_{0}\right]$ that adapts for the hetcroscedasticity. 
Proof: see appendix.

Given $A$, there is only useful infornation in $Z$ if $Y_{\mathrm{n}}$ is conditionally heteroskedastic. However, it is unusual to have a case where one lias a convincing argument (liat $Z$ does not belong in the conditional mear function, but does belong in the conditional variance function. Therefore, in most cases the instrumental variables estimator based on $A$ will be efficient.

Finally, note that if conditions 2 and 3 are satislied but we do not observe $A$, we can still consistently estimate $\alpha$ if we observe a random variable $X$ satisfying

Condition 4. $\quad E[Y \mid A, X]=E[Y \mid A] \quad E[P \mid A, X]=E[P \mid A]$

and $E[P \mid X=x]$ is a nontrivial function of $x$.

Conditiot 4 implies that $X$ affects mean outcomes and treatment probabilities only through its effect on eligibility $A$. In this case we can use $X$ as an instrument instead of $A$. To see this, note that from (7);

$$
E\{E[Y \mid A] \mid X\}=E\left[Y_{0}\right]+E\left[Y_{1}-Y_{0} \mid P=1\right]-E\{E[P \mid A] \mid X\}
$$

whicll simplifies to

$$
E[Y \mid X]=E\left[Y_{0}\right]+E\left[Y_{1}-Y_{0} \mid P=1\right] \cdot E[P \mid X]
$$

This implies that $X$ is a valid instrument. It is cleax that using both $X$ and $A$ as instruments is equivalent to usitg just $A$ because $X$ does not add any information oncc $A$ is known. However, $X$ may be useful if $A$ is not observed. In the example of hise clrafl loltery, one might envision knowing the week a person was born, bul not the exact day. In that case the 
week is the inaccurate instrument $X$ while the aclual day on which a person is born would be the accurate instrument $A$.

\section{4. inference when tije Selected Average Treatment Effect is not Identified.} In this section we discuss what can be learned about treatment effects when Condition 2 is satisfied, but not Condition 3. Therc is no control group of jneligibles, and therefore an essential component of the instrumental variables approach discussed in the previous section is missing. We also assume that $Z$ is discrete with points of support $z_{1}, z_{2}, \ldots, z_{L}$. Lel $p_{x \mathbf{k}}=\operatorname{Pr}\left(P=1 \mid Z=z_{k}\right), \alpha_{k_{k}}=E\left[Y_{1}-Y_{0} \mid P=1, Z=z_{k}\right], \pi_{k}=\operatorname{Pr}\left(Z=z_{k}\right)$ and $Q=\operatorname{Pr}(P=1)=\sum \pi_{k} P_{z_{\mathrm{k}}}$. In terms of these parameters, the selected average treatment effect is equal to

$$
\alpha=\sum_{k} \frac{\pi_{k} \cdot p_{x_{k}}}{Q} \cdot \alpha_{\Sigma_{k}}
$$

The probability limit of the instrumental variables estimator of the parameter $\alpha_{\lambda}$ in the equation

$$
Y=E\left[Y_{0}\right]+\alpha_{\lambda} \cdot P+\left\{\left[\left(Y_{1}-Y_{0}\right)-\alpha_{\lambda}\right] \cdot P+\varepsilon\right.
$$

where $\varepsilon=Y_{0}-E\left[Y_{0}\right]$ and the term in curly brackets is a compound errot term. The instrument vector is $\left[\begin{array}{ll}1 & E[P \mid Z]\end{array}\right]$. This is the optimal instrument when the compound error term is conditionally (on Z) homoskedastic (Newey [1989]). Define

$$
\lambda_{k}=\frac{p_{x_{k}}\left(p_{x_{k}}-Q\right)}{E\left[p_{z_{k}}\left(p_{z_{k}}-Q\right)\right]}
$$


and

$$
\lambda=\frac{E\left[p_{x_{k}}^{2}\right]}{E\left[p_{x_{k}}\left(p_{x_{k}}-Q\right)\right]}>1
$$

The $\lambda_{k}$ are weights that have expectation equal to one, but they can be negative. Note that

$$
E\left[Y \mid Z=z_{k}\right]=E\left[Y_{0}\right]+\alpha_{z_{k}} \cdot p_{z_{k}}
$$

Then we have:

Result 3 The instrumental variables estimator for $\alpha$ using $Z$ as an instrument for $P$ hos probability limit

$$
\alpha_{\lambda}=E\left[\lambda_{k} \cdot \alpha_{z_{k}}\right]=\lambda \cdot \alpha_{0}+(1-\lambda) \cdot \alpha
$$

where

$$
\alpha_{0}=E \frac{p_{x_{k}}^{2}}{E\left(p_{x_{k}}^{2}\right)} \alpha_{x_{k}}
$$

Proof: The first parl follows directly from the expression for $E\left[Y \mid Z=z_{k}\right]$ and the definitions for $\alpha_{z_{\mathrm{k}}}$ and $\lambda_{k}$. To see the second part, write:

$$
\begin{aligned}
& \frac{1}{1-\lambda} \cdot\left[\alpha_{\lambda}-\lambda \alpha_{0}\right] \\
& =\frac{1}{1-\lambda}\left[\frac{E\left[p_{z_{k}}\left(p_{z_{k}}-Q\right) \alpha_{z_{k}}\right]}{E\left[p_{z_{k}}\left(p_{p_{k}}-Q\right)\right]}-\frac{E\left[p_{z_{k}}^{2}\right]}{E\left[p_{z_{k}}\left(p_{z_{k}}-Q\right)\right]} \cdot \frac{E\left[p_{z_{k}}^{2}\right]}{E\left[p_{z_{k}}^{2}\right]} \alpha_{z_{k}}\right]
\end{aligned}
$$

which simplifies to $E\left[p_{s_{k}} \alpha_{x_{k}} / Q\right]$ which is equal to $\alpha$. $\mathcal{Q E \mathcal { D }}$.

$\alpha_{0}$ is a weighted average treatment eftect, with weights proportional to $p_{z_{R}}^{2}$. If the treatment effect is constant, then both $\alpha_{0}$ and $\alpha_{\lambda}$ coincide with the sclocted average treatment 
effect $\alpha$. Therefore if we are prepared to bound the treatment effect heterogencity", we cal calculate bounds for the selected average treatment effect as foilows: Note that $\lambda$ in the above result is estimable from the dala. ${ }^{12}$ Define $c=\alpha_{0} / \alpha$. In terms of $c$ and $\lambda$ the bias of the IV estimator is:

$$
\frac{\alpha}{\alpha_{\lambda}}=\frac{1}{\lambda \cdot c+(1-\lambda)}
$$

Given a choice of $c$, the bound is estimable.

An alternative to bounding the treatment effect helerogeneity is the approach in Imbens and Angrist (1991) where restrictions on the way in which the instrument $Z$ affects participation is employed to identify a local average treatment effect.

5. Conclusion. The SATE measures the average difference between the outcomes of program parlicipants and what participants' outcomes would have been had they not been treated. When some individuals or groupe are ineligible to participate in a program, and eligibility does not affect outcomes for other reasons, the SATE is identified using a simple instramental variables estimalor. This estimator will usually be efficient - it makes full use of the identifying information provided by program eligibility rules.

The possibility of identification through eligibility rules is establislod using the same logic as recent arguments for identification based on the existence of a sel of covariates for which the probability of treatment approaches zero in the limit. The source of identifying

\footnotetext{
${ }^{11}$ This is an alterontjve to bounds on the response variable itself, which is analyzed as in llie context of selection models in Manshi (1991b)

${ }^{17}$ In Amgrist and Krueger (1990) $\lambda$ is estimaled to be abont 2.5 for the solation between quatler of biflh and ligh school graduation.
} 
information is different, however, and likely to be more credible than identification tlrough latenl index models of individual behavior. Progran rules are a matier of public record, and observed data can be used to verify enforcement of the rules. Identification through eligibility rules may also jrovide a good forecast of future program effects under the same rules. Another atisactive feature of this approach is that no eligible participant need be denied treatment in experimental designs based on this principle.

\section{Appendix}

Proof of Theorem 2: The selected average treatment effect $\alpha$ is equal to $(E[Y \mid A=$ 1] $-E[Y \mid A=0]) /(\operatorname{Pr}(P=1 \mid A=1)$. An efficient estimator can therefore be obtained by substituting eflicient extimators for $E[Y \mid A=1], E[Y \mid A=0]$ and $\operatorname{Pr}(P=1 \mid A=1)$ in this formula. We will show that

1) $\bar{Y}_{A=1}$ is an efficient estimator for $E[Y \mid A=1]_{1}$

2) $\bar{P}_{A=1}$ is an efficient estimator for $\operatorname{Pr}(P=1 \mid A=1)$,

3) $\bar{Y}_{A=0}$ is an efficient estimator for $\left.E[Y] A=0\right]$ if the conditional variance of $Y_{0}$ given $Z$ does not depend on $Z$.

There are two steps. First we show that the model can be characterized by a finite number of conditional moment restrictions. Second we show that given those moment, restrictions the three estimators are efficient.

The model implies the following conditional moment restrictions: If $A=0$ then

$$
E[Y-\theta \mid Z]=0 \quad E[P \mid Z]=0
$$


If $A=1$ then

$$
E\left[P-h_{1}(Z) \mid Z\right]=0 \quad E\left[Y-h_{2}(Z) \mid Z\right]=0
$$

The model does not imply any other restrictions. It is essential to show this before proving efficiency using the Chamberlajn bounds The argument goes as follows. Suppose we have a datagenerating process for $(Y, Z, P)$ with $P$ binary, satisfying the mounent conditions. Then we can always construct a model that satisfies (1) and (2) as follows:

$$
E\left[Y_{0} \mid Z\right]=\theta
$$

Choose any nou-constant function for $E\left[Y_{0} \mid Z, P=0\right]$, let

$$
E\left[Y_{0} \mid Z, P=1\right]=\left\{0 \cdots\left(1-h_{1}(Z)\right) E\left[Y_{0}[Z, P=0]\right\} / h_{1}(Z)\right.
$$

and then we complete the model by choosing for all $Z \notin Z_{0}$

$$
E\left[Y_{1} \mid Z_{1} P=1\right]=\left\{h_{2}(Z)-0+h_{1}(Z) \cdot E\left[Y_{0} \mid Z, P=1\right]\right\} / h_{1}(Z)
$$

This constructed model satisfies $E\left[Y_{0} \mid Z\right]=0$ for all $Z$. For this construclion it is essential to have $h_{1}(Z)>0$ which is true when $A=1$ by definition.

Given that the model is fully characterized by the conditional moments, it is straightforward to derive the bounds for the thrce quantities of interest: $E\left[h_{1}(Z)\right], E\left[h_{2}(Z)\right]$ and $\theta$. The formulas in Chamberlain $(1990, \mathrm{p} 7)$ can be applied and simplified directly. First $\theta$. Giver a set of $N_{0}$ observations witl $A=0$, the bound on the variance of $\sqrt{N}_{0}\left(\hat{\theta}-\theta^{\star}\right)$ is

$$
\left\{E\left[\frac{1}{E\left[\left(Y_{0}-\theta^{-}\right)^{2} \mid Z\right]}\right]\right\}^{-1}
$$


This simplifies to $E\left[\left(Y_{0}-\theta^{*}\right)^{2}\right]$ if there is no heteroskedasticity. The variance of $\sqrt{N_{0}}\left(\bar{Y}_{A=0}-\right.$ $\left.\theta^{-}\right)$is $E\left[\left(Y_{0}-\theta^{*}\right)^{2}\right]$. Therefore $\bar{Y}_{A=0}$ is eflicient if there is no leteroskedssticity. In exactly the same way we look at the variance bound for $E\left[h_{1}(Z)\right]$ and $E\left[h_{2}(Z)\right\}$ given a set of $N_{1}$ observations with $A=1$. In both cases the variance is equal to the variance of the average. In other words, $\bar{Y}_{A=1}$ and $\bar{P}_{A=1}$ are efficient estimators.

$\mathcal{Q E D}$. 


\section{REFERENCES}

ANGHIST, J.D., (1990). "Lifetime Earnings and the Vietnam Era Drali Lottery: Evidence from Social Security Administrative Records," American Economic Revieun, June 1990.

ANGkIST, J.D., (1991). "Linear Instrumenlal variables Estination of Average Treatment Effects in Noninear Models," Harvard Institute for Economic Research Discussion Paper No. 1542, March 1991.

-, AND A. IKUEGER, (1991b), "Does compulsory school attendance affect schooling and earnings" Harvard Institute of Economic Research Discussion paper No. 1475, March.

Banow, B., Cain, G., And A. Goldberaer, (1981), "Selection on Observables." Evaluation Studies Reyiew Annals, 5, 43-59, Bev Hills, Sage

Center for Drug Evaluation and Researgh, (1988), "Gujdline fo: the Format and Content of the Clinical and Statistical Sections of a New Drug Application", Food and Drug Adninistration, Department of Health and Human Services, Washington, D.C.: US-GPO.

Cuamberlain, G., (1986), "Asymptotic efficiency in semi-parametric models witla censoring", Journal of Econometrics, 32; $189-218$.

-. (1990), "Efficiency Bounds for Semi-Parametric Regression", Harvard Institute of Economic Research Discussion Paper, No. 1494, June.

EFnon, B., AND D. FEldman, (1991), "Compliance as an Explanatory variable in Clinical Trials, Journal of the American Statistical Association 86 (March 1991), 9-17.

Fernandez, R. L.. (1982), "Enlistment Effects and Policy Inplications of the Educational 
Assistance Test Program," Santa Monica: Rand Corporation.

Fisher, R. A. (1935), "The Design of Experiments", Edinburgl: Oliver and Boyd.

GaRfiNKEL, I., (1983), Evaluation Design for Clild Support Denonstration, University of Wisconsin Instilute for Research on Poverty, Discussion Paper 714-82.

Gakfinkel, I., C. Manski and C. Miollabopoulos, (1990), "Micjo Experiments and Macro Effects", University of Wisconsin Insitute for Research on Poverty", Discussion Paper, 922-90.

Gronav, (1974), "Wage Comparisons - A Selectivity Bias", Journal of Political Economy, 82: $1119-43$.

HaM, J.C. AND R.J. LaLonde, (1990), "Using Social Experiments to Estimate the Effect of Training on Transition Rates, ${ }^{n}$ in Panel Data and Labor Market Studies, edited by J. Hartog, G. Fidder, and J. Theeuwes, Amsterdam: Nort1- Holland.

Harris, J. E., (1985), "Macroexperiments versus Microcxperiments for Health Policy", in: Social Experimentation, edited by J. A. Hausman and D. A. Wisc, Chicago, Unjversity of Chicago Press.

Heckman, J. J., (1976), "The common structure of statistical models of truncation and censoring," Annals of Economic and Social Mcautrment, 5:475--492.

—, (1979), "Sample Selection Bias as a Specification Error", Econometrica, 47(1);153-161.

-, (1990a), "Varieties of Selcction Bias," American Econamic Reniew, 80(2) : 313-318.

—, (1990b), "Randomization and Social Policy Evaluation", mimen, Chicago Uwvorsity, Novem- 
ber 1990 .

-. AND Bo Hovont, (1989), "The Empirical Content of the Roy Model, ${ }^{\text {Econometrica, }}$ (September 1990).

—, AND J. Hotz (1989), "Choosing Among Alternative Nonexperimental Methods for Estimating tise Impact of Social programs: The Case of Manpower Training," Jottral of the American Statistical Association, 84 (December 1989), 862-874.

-, AND R. RoBb, (1985), "Alternative Melhods for Evaluating the Impact of Interventions," in J. Heckman and B. Singer, eds., Longitudinal Analysis of Labor Market Data, New York: Cambridge University Press.

HoT2, J., (1991), "Recent Experience in Designing Evaluations of Social Programs: The Chse of the National JPTA Study", in: Evaluating Welfare and Training Programs, edited by Manski and Garfinkel, Cambridge: Harvard University Press, forthcoming.

IMHENS, G., AND J. D. ANGRIST, (1991), "Identification and Estimation of Local Average Trealment Effects", Department of Economics, Harvard University.

Lalonde, R. J, (1986), "Evaluating the Econometric Evaluations of Training Programs Using Experimental Data," American Economic Review 76(4): 602-620.

MaNsk1, C. F., (1990a), "Nonparametric Botnds on Treatment Eftect", American Economic Review, 80(2), 319-323.

Makskt, C. F., (1990b), "The Selection Problem," University of Wisconsin, Social Systerns Research Institute Working paper 9012, September. 
-, and Inwin Gahfinkel, (1991), Evaluating Welfare and Training Programs, edited by Manski and Garfinkel, Cambridge: Harvard university Press, forthcoming.

Morrit, R. (1991a), "Program Evaluation with Non-Experimental Dala", Iortlicoming in Evaluation Review.

-, (1991b), "Evaluation Methods for Program Entry Effects", in: Evaluatiıg Welfare and Training Programs, edited by Manski and Garfinkel, Cambridge: Harvard University Press, Iorthcoming.

NEWEY, $W_{,}(1989)$, "Efficient Instrumental Variables Estimation of Nonlinear Models", Princeton University Economelric Research Memorandum No 341.

Permutt, Thomas and J. Richard Hebet, (1989), "Simultaneous-Equation Estimation in a Clinical Trial of the Effect of Smoking on Birth Weight ${ }^{n}$ Biometrics, 45 (June): 619-622. Robins, James M. (1989), "The Analysis of Randomized and Non-Randomized AlDS Treatment Trials Using a New Approach to Causal Infercnce in Longitudinal Studies," Health Service Research Methodology: A Focus on AIDS, edited by L. Sechrest, H. Freeman, and A. Bailey, NCHSR, U.S. Public Health Service.

Rosenbaum, P.R. AND D.B. Rubin, (1983), "Assessing Sensitivity to an Unobscrved Binary Covariate in an Observational Study with Binary Outcome," Journal of the Royal Statislical Sorietty Series B, 45(2): 212-218.

RoYall, M., (1991), "Ethics and Statistics in Randomized Clinical Trials", Statistical Scicnce, $6(1): 52-88$. 
RubiN, D. (1974), "Estimaling Causal Effects of Treatments in Randomized and Non-randomized Studies," Joumal of Educational Psychology, 66(5): 688- 701.

Rubin, D., (1977), "Assigment of Treatment on the Basis of a Covariate," Joumbl of Educational Statistics, $2(10): 1-26$ 